\title{
Teaching Segmental Features to EFL Learners
}

\author{
Guillaume Marie KANAYANDU BETU \\ Chef de Travaux \\ Université Pédagogique de Kananga RDC
}

\begin{abstract}
English Pronunciation is very important in the learning of English and has equally attracted the attention of teachers and researchers. In this respects, the aim of this paper is to provide EFL teachers with some methodological guidelines that may help them facilitate the teaching of segmental features. The study shows that pronunciation is important for oral communication and is also closely linked with other aspects of language such as grammar, vocabulary, listening comprehension, etc. This work also justifies the choice of using RP rather than GA when teaching pronunciation to EFL learners in the Democratic Republic of Congo for it takes into account both aspects of oral communication, i.e., understanding what you are listening and making understood.Furthermore, in DRC, most available materials in English Language teaching are presented in RP although GA is the most powerful and widespread around the world. As for the teaching of segmental features, the author suggests that the teacher present the sound feature in words put in a context, using the teaching aid, insisting on the production of the sound, and asking learners to interact as they do in a vocabulary or grammar lesson.
\end{abstract}

\section{Introduction}

Teaching pronunciation is well-thought-out as a conundrum for most EFL teachers and pronunciation has turned out to be the most challenging skill or subskill to be taught to EFL learners.Furthermore,the inability of many adult second language learners to achieve proficiency in pronunciation has often intrigued linguists. In this paper, we would like to give some methodological guidelines one may take into account while teaching English segmental features. We are then going to highlight the importance of correct pronunciation in teaching EFL learners, justify the choice of the model of pronunciation to be taught before dealing with some implications for teaching pronunciation to EFL learners and eventually present how an English teacher may proceed to teach English segmental features.

\section{The importance of Correct Pronunciation in English Language Learning}

In fact, pronunciation is a compulsory skill for any English learner and as put by inglesconprofepablo.com (2018), good pronunciation is important for perceived competence, that is, many native speakers will think a second language English speaker has a low level of fluency if his/her pronunciation is inappropriate. Pronunciation is alsoessential for clarity and intelligibility, this means, one should speak with a correct pronunciation for his/her mistakes may impair intelligibility and impede him from being understood.Furthermore, good pronunciation helps the learner acquire English faster. Indeed, the earlier you master the basics of English pronunciation, the faster you'll become fluent. Unquestionably, pronunciation is an integral part of language learning and teaching and as Wennestrong (1992)put it, "pronunciation broadly includes both segments of a language, and suprasegmental features of which stress, rhythm, intonation and linking are organizing structures". Of course, the organization of sounds plays a greater role in communication than the sounds themselves. Thus pronunciation is important for oral communication. It is also linked with other skills and sub skills such as listening comprehension, spelling, grammar and reading. Consequently, pronunciation bears important information that can support these skills. In fact, the understanding of the connotation between pronunciation with greater significance and therefore shows as it has been put by Katsuva (1987:232) that "pronunciation is the primary medium through which we bring our use of language to the attention of other people". Stevick, quoted by Katsuva (1987:232) assumes that pronunciation "is potentially useful in many situations indispensable". As a matter of facts, pronunciation is closely linked with other aspects of language. Simo Bobda (1993) goes along with the preceding assumption when she argues that, the spread of English throughout the world gave birth to new Englishes which have brought about innumerable deviant forms at the level of grammar, vocabulary and pronunciation displays the highest number of deviation ...too much tolerance in the teaching of pronunciation in non-mother tongue environment has a greater effect on intelligibility, spelling and literary understanding.

On the other hand, listening comprehension is really important in order to interpret speech accurately. Therefore, listeners or learners of a given language need to know how speech is organized and what or which patterns of intonation speakers need to employ. 
These suprasegmental aspects such as stress and intonation may alter largely or considerably the temperamental impact of what we hear. They also make the difference subtle between a polite request and an abrupt demand, that is, for instance, a question may be interpreted as a statement of fact if pronounced with incorrect pronunciation and as a result a communication breakdown occurs. As for the learners' spelling of English, it may also be affected by pronunciation in that novice learners expect to have a one-to-one correspondence between a sound and its spelling and their difficulty with the pronunciation originates from a misinterpretation of the spelling system rather than difficulty with the pronunciation of a sound. It should be pointed out that pronunciation can also convey grammatical information and this may be shown through these two groups of words given by Rita Wong (1993):

(1) I'm sorry. You can't come with me.

(2) I'm sorry you can't come with me.

In writing, the difference between the two groups of words is obvious in that punctuation and capitalization make it clear. But in speech, the difference is made thanks to rhythm and intonation, that is to say, in the first group of words, there is a rise and fall pitch on sorry followed by a pause that plays the same role as a period and consequently the two parts of this group of words make two different ideas and therefore presuppose a refusal or rejection on the part of the speaker. Whereas in the second group of words, there is only rise and fall on come that indicates that there is only one idea presupposing a regret on the part of the speaker. This example shows how rhythm and intonation can perform grammatical function. As for reading, a lack of knowledge of pronunciation can affect it simply because the mispronunciation of a word may lead to misidentification of it and as Rivers (1981:36) put it, "facility in reading could not be developed unless the students were trained in correct pronunciation..., and the use of simple speech patterns". Indeed, as suggested by Wong (1993), to ignore pronunciation it to ignore important information that can support these other skills and sub skills.

Unquestionably, "a language is what its native speakers say and not what someone thinks they ought to say" (Rivers, 1981:42), it is better to have the correct pronunciation, that is, the one accepted by native speakers. In fact, correct pronunciation has become an important subject since a language, if it is to be understood, must be uttered and expressed as by its native speakers or in a way that is understandable by the native speakers; the speakers ought to have a near native pronunciation of the target language.

It should be noted, however, that each language has its own set of sounds which are different from those of other languages, it is what we call the sound system. Thus, when we utter words, they are meaningful with regard to their pronunciation and consequently the mispronunciation of certain words may lead to unacceptability and unintelligibility and therefore distort the meaning of the word. Mention should be made also of the fact that "it is quite common to communicate with someone who has a noticeable accent" (Chastain, 1976:338) for the speaker's venerability depends on the judgment the listener makes of him and great prestige is still attached to this.

To sum up, correct or good pronunciation should be the ideal of both learners and teachers of English as a foreign language. They should therefore fight to have a good pronunciation to have their speech acceptable and intelligible to their interlocutors. Thus, much emphasis should be put upon correct pronunciation and intonation since "language is speech and not writing" (Rivers, 1981:141). This assumption goes along with the order of presentation, that is, listening and speaking before reading and writing and as O'Connor (1980:1) argues "language starts with ear". Eskenazi (1999: 66-67), in his turn, argues that below a certain level, even if grammar and vocabulary are completely correct, effective communication cannot take place without correct pronunciation because poor phonetics and prosody can distract the listener and impede comprehension of the message.

\section{The choice of Models of Pronunciation in English Language Learning}

The spread of English all over the world has given birth to new Englishes which, unquestionably, have brought into existence many shifts especially in pronunciation. This prevalent use of the English language, has brought forth distinctive accents. Thus, as asserted by Donald (1978: VII), when one wishes to write a manual on pronunciation for a language to be studied in a classroom and especially when that language is English, one of the unavoidable problems he has to meet is that of the choice of the dialect to be taught for English is a language that is largely spoken over vast areas of the world. Not only does this phenomenon occur in countries where English is spoken as a second or foreign language but also even in Britain itself where it is spoken as the mother tongue of most of the inhabitants. That is to say, be it in Britain, or elsewhere, English occurs in various dialect forms and is greatly diversified in accordance with regional areas where it is spoken. Thus as suggested by O'Connor $(1980)$ and Brown $(1974,1977)$ cited by Katsuva (1987:234), the most sensible thing to do when being faced to such a problem is to choose as a model the sort of English that the learner is likely to hear most often. From what precedes comes out the question "what form of pronunciation is to be taken into account as a model for both Congolese learners and teachers of English?" 
This question seems crucial since English is learned in the Democratic Republic of Congo as a foreign language and therefore is not used for everyday communication. To answer this question, Gimson (1981:301) gives decisive criteria upon which the choice of any teaching model must be based. He states that this basic model should:

- have work currency

- be widely and readily understood,

- be adequately described in textbooks and have ample recorded materials available for learners.

These criteria being accounted for, the choice is effectively between Received Pronunciation (RP), the accepted social standard of pronunciation in Britain and General American (GA), "the type of pronunciation that has the best claim in American as asserted by Kuryatnikova et al (1993. Although GA is now completely accepted in Britain (Gimson, 1981), most Congolese learners and teachers of English still stick to the long-standing tradition of learning or teaching English that is based on the Received Pronunciation for not only does it reflect international intelligibility but also as Brown (1977) cited by Katsuva (1987:234) argues,RP is the only accent of which several segmented and international descriptions are readily available, it is the accent which is most usually taken as a model for foreign students and finally, it is the accent towards which many educated speakers of other accents tend to. And therefore, most of the available materials, in DRC, are presented on the basis of RP.

In brief, within the scope of our research, the RP model is chosen rather than GA for it takes into account both aspects of oral communication, i.e., understanding what you are listening and making understood, which Brown says, should be aimed at in teaching pronunciation. Furthermore, in DRC, most available materials in English Language teaching are presented in RP although GA is the most powerful and widespread around the world.

\section{Prerequisites for Teaching Pronunciation to EFL Learners}

To begin with, some prerequisites in the teaching of pronunciation should be taken into account before speaking of the actual teaching of pronunciation.

\section{a. Teachers must be well trained}

In fact, to teach pronunciation, teachers should possess, a good knowledge of phonetics and phonology. They have to know how the sounds are formed and produced, how the speech organs behave and how the voice pitch is utilized to convey meanings and feelings. Not only do they need to be quite knowledgeable in the area of speech production but also in the area of speech perception. In speech perception, we focus on how we perceive or hear the sounds, which basically affect the manner in which you produce these sounds. Indeed, to cope successfully with the teaching of English pronunciation, it is required that the teacher be well trained. The teacher should have an ear trained to recognize the distinction between speech sounds if he is going to correct pronunciation, to detect or perceive and discriminate the sound of the new language. In addition, he should be trained to control the organs of speech, that is, he should be able to recognize the correct or wrong sound when he hears it and make it as well. As stated by Hycraft (1982), a precise knowledge of where and how sounds are formed in the mouth enables the teacher to diagnose the reason for the fault even though it may be the usual one. Furthermore, the teacher must be able to see the mistake as well as he hears it or the correction will be in vain. Once you determine the cause of error, which is often attributed to the influence of the students' L1, then you're able to diagnose and instruct accurately and effectively.

To sum up, the teacher should have the knowledge of articulatory phonetics. Mention should also be made of knowing what kinds of errors should be corrected and when they should be corrected. Of course, in language education, we suggest that errors that impair intelligibility of a message should have top priority for correction. To the question of when and how these pronunciation errors should be corrected, Holly and King provide the answer according to which teachers should allow the learner to complete his statement although it is incorrect. They should be patient, tolerant and flexible as well. In other words, the teacher should ignore errors in pronunciation while the learner is engaged in oral communicative language work. The learner should not be interrupted for correction will inhibit his fluency in speaking. Thus correction of pronunciation should be done in a general way some minutes after the language activity.

\section{b.Teachers must use appropriate teaching aids}

Another precondition in teaching pronunciation is the didactic material. Unquestionably, like vocabulary or grammar lessons, a pronunciation lesson needs didactic materials among which drawings, pronouncing dictionary, tapes, records, films, CD, video and language laboratory. Drawings of the speech organs can help learners to see which organ is used to produce such sounds. The pronouncing dictionary, as well, can help learners to learn the correct pronunciation unless they have been trained to use it. On the other hand, tapes, records, films videoand language laboratory offer the learners an opportunity to be brought directly into contact with the authentic native pronunciation and hence compare their own pronunciation with that of the native speaker.

\section{c. SL learners must hear different sources of input.}


Celce-Murcia et al (1996: 18) suggested that the optimal situation would be to learn from many different native teachers, thus exposure to different kinds of input. As for Cook (1996: 130), all types of input are beneficial: teacher's language,conversation CDs, advertisements from television and magazines, DVDs, other students' interlanguage, train time-tables,etc. Thus, language may come first from the teacher providing students with authentic language, defined as "language constructed to fulfill some social purpose in the language community" (Cook, 1996: 123). Exercises and courses had then to turn away from specially constructed classroom language (non-authentic language) to pieces of language that had been really used by native speakers (authentic language).

Furthermore, an English environment should be created to allow learners overcome some of their pronunciation difficulties. Thus, apart from the classroom where learners are exposed to the target language, the exposure to English pronunciation can be achieved by creating English clubs of which teachers, learners and any speaker of English are members. Thus learners will be exposed to the target language through different English club activities such as debates, parties, conferences, films, theatre, etc.

\section{d.SL learners must produce large quantities of output.}

In fact, producing language serves second language acquisition in several ways. For instance, it enhances accuracy and fluency. According to research, learners need opportunities to practice language at their level of English language competency. This practice with English-speaking peers is called Comprehensible Output. Many researchers feel that comprehensible output is nearly as important as input. Cooperative learning groups are one way for new learners of English to receive plenty of understandable input and output.

\section{e. SL learners must receive good feedback}

Indeed, SL learners should feel at ease in the SL classroom. According to Eskenazi (1999: 73), student's confidence can be increased by correcting them only when necessary, reinforcing good pronunciation, and avoiding negative feedback. Therefore, one to one instruction is beneficial as it allows students to practice in front of the teacher alone, until they are comfortable with the newly-acquired sounds. Adapting feedback to the amount of interruption that each student can tolerate is another way to avoid discouraging active production and to obtain better results from correction. When learners are forced to produce sounds that do not exist in their native language in front of their peers, they tend to lose self-confidence (Eskenazi, 1999:73). As a result, they may stop trying to acquire SL pronunciation relying on FL sounds. Adult learners need to feel self-confident and motivated in order to produce new sounds without inhibition. Learners who are ill at ease have a higher risk of performing poorly, or even abandoning the phonological component completely.

\section{The Teaching of English Segmental Features}

One of the first issues that must be taken into account when trying to teach pronunciation in the classroom is that there is not just one method for teaching languages. The teacher has to adapt his methods and techniques according to several elements, such as the age of the students, the goals of the class, the material available for activities, etc. In the case of oral skills reinforcement or pronunciation classes, the teacher should have a special effective way to show the students the symbols and their corresponding sounds, together with recordings of native speakers, spelling exercises and modulation techniques, among othersGimson (1981) argues that the teaching of pronunciation presents particular difficulties for pronunciation does not permit a progressive treatment since all phonetic or phonological features are potentially present from the very first lesson. However apart from occasional teaching pronunciation through lessons such as vocabulary and grammar, the teacher should present and practice systematically points of pronunciation as he introduces other aspects of the language.

Herein, we are going to attempt to provide some general considerations and techniques that may be useful while teaching features of the English sound system.Before teaching learners to produce a difficult sound, Rivers and Temperley (1978:10) advise to begin by considering sources of difficulty in the learners' native language. The teacher should be aware of these sources and be able to help his learners with specific habits.As to the presentation of the sounds, the teacher must select the sounds and present them in context, which sounds must be included in sentences or dialogues.Lewis and Hill (1985:67) in their turn provide the way in which sounds must be taught. As for them, the teacher should make us of choral pronunciation for it serves to bring the class together. They suggest that the ideal solution is what they call "choral and individual pronunciation" (c.i.p.). That is to say the class repeats in chorus the model pronunciation provided by the teacher and thereafter the teacher asks learners to reproduce it individually.

On the other hand, Oliva (1969:100-109) suggests that repetition of sounds is one of the techniques a teacher will use in teaching pronunciation. Indeed, repetition is not the sole sufficient technique. He supplements it by additional techniques stated as follows in seven steps: 
1.The teacher identifies all the sounds of the foreign language he is to teach (sounds that are distinctive), that is, the phonemes of the language. He should quickly point out that letters of the alphabet are not identical with the sounds of a language;

2. Identify the sounds of the language that are most difficult for the learner;

3. The teacher can supply a near English equivalent sound if there is one;

4. The teacher should tell the learner where he will frequently encounter the sound in the language;

5 . He describes how the sound is made with the speech organs;

6 . He proceeds to provide adequate practice in the" formation of sounds;

7. He uses the phonetic symbols to indicate a particular sound.

As can be seen, from the above different views on the teaching of sounds, the process lies in presenting the sound in context, having it repeated by the learners after the teacher had provided the model pronunciation. In addition, follow up discrimination exercises and minimal pair exercises should be provided.

In brief, in presenting and practicing all the features of the sound system, mention should be made of three basic steps:

1. The teacher presents a sound feature in a context and pronounces it, he repeats if three or four times while learners are listening;

2. Learners produce the same sound feature after having listened to the teacher's model (tape, cassette recording or $\mathrm{CD})$;

3. The teacher provides pronunciation exercises and feedback.

In other words, the teacher presents the sound feature in words put in a context, using the teaching aid, insisting on the production of the sound, asking learners to interact as they do in a vocabulary or grammar lesson. The summary is built up as in all other lessons. During the practice stages (controlled and free practice), apart from reading the summary and building sentences containing the learned feature, minimal pair exercises should be used to allow learners to discriminate the sound from other similar sounds such as for the case the sound

$\begin{array}{lllrr}\text { /æ/e.g.up/at } & \text { hut/hat } & \text { bud/bad } & \text { drunk/drank } & \text { cut/cat } \\ \text { luck/lack } & \text { run/ran } & \text { but/bat } & \text { bun/ban } & \text { cup/cap } \\ \text { lump/lamp } & \text { much/match } & & & \end{array}$

Discrimination exercises are very important since they help to avoid confusion such as in the following cases:

1. I'll get you a big cap vs. cup.

2. That cat needs attention vs. That cut needs attention.

3. The cupboard was full of old rags vs. rugs.

Discrimination may also be done in repeating sentences containing both the target sound and the one confused with after the teacher chorally and then individually:

1. My young brother is married.

2. There was nothing much the matter.

3. I wonder if the judge was mad.

4. A monkey took my uncle's hat.

5. He cut his hand on a rusty lamp.

Eventually, after the free practice stage comes the feedback which is the last one.

\section{Conclusion}

Of course, pronunciation is a very difficult domain for a foreign language to acquire for each language has its characteristics and interrelated mouth position. From this viewpoint, the problems or difficulties are related to the nonexistence of features that do not have counterparts in the source language. To teach segmental futures, the sound feature should be presented in words put in a context. The teacher insists on the production of the sound and uses the teaching aid. He asks learners to interact and then builds the summary as in all other lessons.During the controlled and free practices, apart from reading the summary and building sentences containing the learned feature, minimal pair and discrimination drills exercises should be used Indeed, pronunciation teaching techniques are numerous and diversified. Those we have singled out are but some of them. But we believe that if they are used with tact and with didactic materials, they may be helpful in teaching all the features of the sound system. 


\section{References}

BOBDA, A.S. 1991. "Does Pronunciation Matter?" in Forum, Vol.29, n4 CELCE-MURCIA, et al. 1996. Teaching Pronunciation. Cambridge: Cambridge University PressCHASTAIN, K. 1976. Developing Second Language Skills, University of Virginia COOK, V. 1996. "Language and Input in the L2 Classroom". Second Language Learning and Language Teaching. Ed. Vivian Cook. New York: Arnold, 118-33.

DONALD, J.P. 1978. Patterns of English Pronunciation, Massachusetts. ESKENAZI, M. 1999. "Using Automatic Speech Processing for Foreign Language PronunciationTutoring: Some Issues and a Prototype". Language Learning and Technology 2.2 62-76.

GIMSON, 1981. An Introduction to the English Pronunciation, New ed. Edward Arnold. HYCRAFT, D. 1986 An Introduction to the English Language Teaching, Oxford: OUP.INGLESCONPROFEPABLO.COM. 2018

KANYANDU, B. 1994. Phonological Fossilization in the Acquisition of English: Investigation in some Schools of Kananga. A Thesis Submitted in Partial Fulfillment for the Degree of BA Honours in Applied Pedagogy; Option: English. ISP Kananga, DRC.

KANYANDU, B. 1999. Teaching English Pronunciation to EFL Learners in Annales de l'ISP Kananga Vol. IX,N 1:1 - 9.

KATSUVA, N. 1987. An Analysis of Pronunciation Errors in the Acquisition of English by Nande Native Speakers. Unpublished PhD dissertation, Essex University. KURYATNIKOVA, E., et al. 1991. Teaching American Communication in Forum, Vol. 29, $\mathrm{n}^{\circ} 4$

LEWIS,M., \& Hill. 1985. Practical techniques for Language Teaching, London: Language Teaching Publication.CONNOR, J.D. 1980. Better English Pronunciation, Cambridge: CUP. OLIVA, P.F. 1969. The Teaching of Foreign Language, New Jersey: Practice Hall, Uno, Engle- Wood Cliffs. IVERS, W.M. 1981. Teaching Foreign Language Skills, $\quad$ Chicago: CUP.RIVERS, W.M., et al. 1978. A Practical Guide to the Teaching of English as a Second or Foreign Language, New York: OUP. WENNERSTRONG, A.K., 1992, "Content Based Pronunciation" in Tesol Journal. Vol. 1 n³.WONG, R. 1986. "Pronunciation, Myths and Facts" in Forum Vol. 31, n 4. 